\title{
Barriers of Thrombolysis Therapy in Developing Countries
}

\author{
Kavian Ghandehari ${ }^{1,2}$ \\ ${ }^{1}$ Neuroscience Research Center, Mashhad University of Medical Sciences, Mashhad, P.O. Box: 91766-99199, Iran \\ ${ }^{2}$ Department of Neurology, Ghaem Hospital, Ahmadabad Street, Mashhad, P.O. Box: 91766-99199, Iran
}

Correspondence should be addressed to Kavian Ghandehari, kavianghandehari@yahoo.com

Received 18 December 2010; Revised 31 January 2011; Accepted 13 February 2011

Academic Editor: Bruce Ovbiagele

Copyright (c) 2011 Kavian Ghandehari. This is an open access article distributed under the Creative Commons Attribution License, which permits unrestricted use, distribution, and reproduction in any medium, provided the original work is properly cited.

\begin{abstract}
The developing world carries the highest burden of stroke mortality and stroke-related disability. The number of stroke patients receiving r-tPA in the developing world is extremely low. Prehospital delay, financial constraints, and lack of infrastructure are main barriers of thrombolysis therapy in developing countries. Until a cheaper thrombolytic agent and the proper infrastructure for utilization of thrombolytic therapy is available, developing countries should focus on primary and secondary stroke prevention strategies. However, governments and health systems of developing countries should efforts exerb for promotion of their infrastructure of stroke care.
\end{abstract}

\section{Introduction}

The stroke in developing countries has grown to epidemic proportions [1]. Two-thirds of global stroke occurs in lowand middle-income countries [1]. Most of the available stroke data from these countries are hospital series $[1,2]$. There has been limited progress in management of patients with stroke in developing countries and data on stroke care in these countries are sparse [3-5]. Guidelines are continuously developed and updated in the developed world but their practicality for use in developing regions is unrealistic [6]. The number of stroke patients receiving $\mathrm{r}$-tPA in the third world is extremely low [7]. Stroke thrombolysis is currently used in few developing countries like Brazil, Argentina, Senegal, Iran, Pakistan, China, Thailand, and India [7]. The objective of this paper is assessment of barriers and limitations of thrombolysis therapy with rtPA in developing countries.

\section{Prehospital Barriers}

One of the most important prehospital barriers of thrombolysis therapy in the developing world is nonrecognition of stroke warning signs by patients at risk, families, the general public and even health workers in some places [8]. There is poor recognition of stroke symptoms in developing countries [9]. The people at the highest risk have the lowest knowledge regarding vascular disease including limitations to ascertain mild and transient symptoms as stroke [10]. Most stroke patients attending a university hospital in India were not aware of the importance of the time window in stroke management [11]. Only one in 25 patients attending a stroke clinic and $27 \%$ of patients presenting to the stroke services in a tertiary care hospital in India were aware that they had suffered a stroke [11]. Production and broadcasting of stroke awareness programs by TV and other media could reduce the stroke onset to hospital entrance time [12]. There are also cultural and religious barriers that impede early presentation, even when stroke is recognized. Half of the patients with stroke in Bolivia do not go to hospital or see a doctor, thus consideration of health behavior is important in different population [13]. In developing countries, there is great variation in the time taken by patients to arrive to hospitals [8]. The median time to admission of stroke patients in Gambia and Ethiopia is 8 hours and 13.5 hours, respectively [8]. The proportion of stroke patients who reached the hospital within the 3-hour window period in Iran and India is $8 \%$ and $14.7 \%$, respectively [14, 15]. Although there is hardly any ambulance service especially in rural areas in most of the developing countries [3, 7], in Iran there is a well organized ambulance service which covers the rural areas [16]. However about half of the Iranian urban population choose to deliver their patients by personal vehicles $[14,16]$. 


\section{Financial Constraint}

One of the main reasons of low utilization of thrombolytic therapy in these countries is financial constraints because recombinant tissue Plasminogen Activator ( $\mathrm{r}$-tPA) in developing countries has high cost (US\$ 1400 per person) [7]. The developing world, with a population five times the size of developed world, has at its disposal only $25 \%$ of the global gross domestic product [17]. The budget allocation to health care is often meager, most of which goes to establishment and running costs [17]; for example, governments of Pakistan and Iran spend $0.72 \%$ and $5.4 \%$ of gross national product on health care which equals to about US\$ 3.5 and US\$ 7.5 per person per year, respectively $[16,18]$. Thrombolysis with r-tPA for stroke is not registered by governments in most of the developing countries and health insurance companies do not cover the high cost of thrombolysis therapy for stroke patients because the governments do not pay for this expensive therapy to these companies [7]. Countries in the developing world where r-tPA is approved by the local regulatory authorities for use in acute ischemic stroke include, China, Philippines, Malaysia, Turkey, Thailand, Argentina, Brazil, Peru, Bulgaria, Czech Republic, Estonia, Slovakia, Ukraine and Poland [7]. In other words the most governments in developing countries are not in a position to provide thrombolysis therapy in public sector hospitals to patients in need $[3,7]$. Furthermore, stroke physicians are not paied for thrombolysis therapy by government and health insurance companies [16]. Therefore thrombolysis therapy is feasible in hospitals of private sectors which cover a limited number of stroke patients. Stroke patients in these countries should cover the cost of r-tPA by their own personal savings or not receive treatment [7]. Only 30\% of Iranian stroke patients could pay the cost of r-tPA by their own savings and thrombolysis therapy in India is mainly performed in some private hospitals [14]. A study from south India reported that $30 \%$ of stroke patients reached the hospital within 3 hours postevent and 16\% were eligible for thrombolysis therapy but all of these eligible patients belonged to a lower socioeconomic group and could not afford the therapy due to its high cost [15]. Among 23 stroke patients admitted in a private hospital in northwest India who were eligible to intravenous thrombolysis, only five actually received the drug and the remaining patients were unable to afford the high cost of the treatment [19]. The cost of r-tPA in India amounts to EUR 1300 per patient. The approximate cost for the secondary prevention of stroke in India is EUR 9 per month for each patient (using two antihypertensives, one antiplatelet agent, and a statin) which is much cheaper than r-tPA [7]. Some health maintenance organizations in developing countries, for example, Argentina, do not cover/reimburse for thrombolytic therapy despite its approval for stroke therapy by health authorities $[7,20]$. The Argentina health system annual revenue in recent years has been approximately $7 \%$ of the gross national product. However, $40 \%$ of the Argentine population does not have medical insurance which receive medical attention free of cost at public hospitals [21]. Governments must understand the importance of vascular disease prevention and treatment and assign sufficient resources for this purpose. In Spain as a developed country, the impact of thrombolysis on society's health and social budget indicates a net benefit after 6 years and the improvement in health grows continuously [22].

\section{Lack of Infrastructure}

Infrastructure is another barrier against thrombolysis in developing world. A general overview shows that the quality and quantity of stroke care is largely patchy in low developed and medium developed countries with areas of excellence intermixed with areas of severe need depending upon location and socioeconomic status [9].

Centers with resources and infrastructure for thrombolysis in stroke patients are very limited in the developing world [7]. A national survey in Poland showed that only 15\% of stroke patients were admitted in specialized stroke units [23]. Although about 14 hospitals have this resource and infrastructure in Iran with 75 million population and stroke units are increasing upto 20, these medical centers cover less than one third of Iranian stroke patients [14]. About 15 stroke units in India with more than 1 billion population use r-tPA for acute stroke [7]. Unfortunately, most of the centers with the resources to facilitate thrombolysis therapy in India are in the private sector. Hyperacute thrombolysis was found useful and safe in selected patients with ischemic stroke in India [24]. In China, 40\% of 1500 neurology departments have the infrastructure to facilitate thrombolysis therapy for a population of 1.3 billion [25]. Stroke patients who underwent either CT or MRI in China and Iran constitutes $83 \%$ and $95 \%$ of these patients, respectively $[14,25]$. In the African continent, the situation of stroke care is much worse; only northern African countries and South Africa have an appropriate number of CT and some MRI scanners [26]. Nine percent of stroke patients in Nigeria and 38\% of the stroke patients in Ethiopia could afford to have CT scans [27, 28]. The stroke unit model of care in South Africa has not been widely implemented despite compelling evidence of efficacy [29]. Currently there is 1 comprehensive acute stroke unit in Cape Town [29]. Therefore thrombolysis therapy with r-tPA in Africa is a dream. Except Brazil and Argentina, well-organized stroke services in the government sector are virtually absent in South America [7]. There are about 20 hospitals in Brazil where intravenous thrombolysis is administered [12]. The majority of stroke patients are treated in public hospitals in Brazil through a united health system. Emergency ambulance services are being widely available in Brazil [12]. The health care system in Argentina provides limited incentives to health care providers and hospitals to offer specialized care for stroke patients [21]. Seven stroke units have been built in Argentina however, $1.3 \%$ of stroke patients in Argentina receive thrombolysis therapy and $6.9 \%$ are admitted in the stroke unit $[20,21]$. Thus availability of skilled manpower to deliver thrombolysis and multidisciplinary care in a dedicated stroke unit is very limited in developing countries. The mean hospital entrance to completed investigations time in early arrived Iranian stroke patients was 116 minutes [14]. Delay in performance 
of CT, and laboratory tests excluded $56 \%$ of Iranian early arrived stroke patients from 3 hours time window and is a problem of this therapy in Iran [14]. This delay is due to lack of priority for candidates of thrombolysis in performance of triage, CT and laboratory tests [16]. Avoidance of this delay increases upto 2-3 times the number of eligible Iranian stroke patients for intravenous r-tPA [16]. Lack of priority of stroke patients in emergency division and CT scan facility caused a high mean door-to-needle time (120 minutes) in Pakistan [18]. The mean door-to-needle time was $27 \mathrm{~min}$ in a public sector hospital in New Delhi, $72 \mathrm{~min}$ in Thailand and $21 \mathrm{~min}$ in Taiwan [30-32]. A study on stroke evaluation in Buenos Airos university hospital revealed that $24 \%$ of stroke patients arrived within 2 hours postevent to the emergency room and $2 \%$ had a CT within under 2.5 hours [33]. Fourteen percent of stroke patients who received thrombolytic therapy with r-tPA in Pakistan developed fatal hemorrhage and 10\% of them had nonfatal hemorrhage [18]. Protocol violations were found in $33 \%$ of these treated stroke patients [18]. This may be a part of learning curve and it clearly identifies a need of educating physicians involved in stroke care. Another possible explanation for the increased rate of the intracranial hemorrhage in Pakistan could be related to genetic variability [18]. Higher rates of r-tPA-related intracranial hemorrhage among Asians due to racial differences in blood coagulationfibrinolysis factors is reported in Japanese stroke patients [34]. These racial differences in developing and developed countries of Asia could affect the cost and benefit ratio of thrombolysis therapy. The number of medical centers with interventional facilities for intraarterial thrombolysis with r-tPA in some developing countries like Brazil and Senegal is surprisingly more than stroke units [7]. In most of the developing countries, for example, Iran and Pakistan this condition is reverse [7]. However, number of Iranian stroke patients who have been treated with intraarterial r-tPA is surprisingly more than patients who were administered intravenous r-tPA [16]. There are two reasons for this discrepancy. First, the dose of r-tPA for intraarterial administration is one-third of its dose for intravenous route and this matter makes intraarterial thrombolysis cheaper in Iran and some of the developing countries. Second, Intraarterial r-tPA therapy extends therapeutic time window up to 6 hours or more and only $44 \%$ of early arrived Iranian stroke patients remain within 3 hours time window at completion of CT and laboratory workup due to lack of priority of these patients for triage and investigations $[14,16]$.

\section{Promotion of Infrastructure}

Some of the developing countries have been promoting infrastructure for stroke care in the recent three years. The Brazilian program for establishment of stroke network initiated in 2008. Four levels of stroke hospitals defined in Brazilian program were: (1) Level A: a comprehensive stroke center, (2) Level B: a hospital with neurologist and $\mathrm{CT}$ available $24 \mathrm{~h}$ a day but without MRI or endovascular interventions, (3) Level C: a remote center for thrombolysis with telemedicine connected to a Level A center (for areas without a neurologist, and (4) Level D: a hospital without structure for thrombolysis. In each state, the program was tailored according to the local conditions (infrastructure and technical staff). The program will be expanded to 15 of the 26 states [35]. A stroke program has been created in the Russian Federation since 2007, in which each region of Russia will have 1 to 3 comprehensive stroke centers ( 1 center per 1.2 to 2 million population). Each comprehensive center will be connected to a network of 3 to 6 primary stroke units with telemedicine. The program is financed from federal budget and from budgets of constituent territories of the Russian Federation. Four hundred sixty-three patients received treatment with r-tPA during over the 9 months of 2009 within Russian stroke program [35]. The new system of stroke care will be deployed in all 83 regions of Russia by 2013 [35]. In South Africa with only one comprehensive stroke unit, a stroke training course was developed for nurses and allied professionals and has attracted staff from other local hospitals [29]. This stroke unit has assisted in the establishment of stroke services and units at other hospitals in both the public and private sector [29]. Some recent reports support the use of thrombolytic therapy in stroke patients in previously inexperienced centers by using guidelines created by clinical trials of intravenous thrombolytic therapy $[36,37]$.

\section{References}

[1] V. L. Feigin, "Stroke epidemiology in the developing world," The Lancet, vol. 365, no. 9478, pp. 2160-2161, 2005.

[2] K. Ghandehari and Z. Izadi Mood, "The Khorasan stroke registry: results of a five-year hospital-based study," Cerebrovascular Diseases, vol. 23, no. 2-3, pp. 132-139, 2007.

[3] N. Venketasubramanian, "Stroke in developing countries," in Current Review of Cerebrovascular Disease, M. Fisher and J. Bogousslavsky, Eds., pp. 212-214, CM Publications, Philadelphia, Pa, USA, 2nd edition, 2001.

[4] K. Ghandehari and Z. Izadi Mood, "Cardioembolic strokes in Eastern Iran and the importance of rheumatic valvular disease," Turkish Journal of Medical Sciences, vol. 36, no. 6, pp. 361-364, 2006.

[5] K. Ghandehari and Z. Izadi Mood, "Incidence and etiology of ischemic stroke in Persian young adults," Acta Neurologica Scandinavica, vol. 113, no. 2, pp. 121-124, 2006.

[6] K. Hill and E. Lalor, "Clinical guidelines for stroke care: why the fuss and is there opportunity for collaboration?" International Journal of Stroke, vol. 3, no. 3, pp. 173-174, 2008.

[7] J. D. Pandian, V. Padma, P. Vijaya, P. N. Sylaja, and J. M. K. Murthy, "Stroke and thrombolysis in developing countries," International Journal of Stroke, vol. 2, no. 1, pp. 17-26, 2007.

[8] R. F. Yu, M. C. San Jose, B. M. Manzanilla, M. Y. Oris, and R. Gan, "Sources and reasons for delays in the care of acute stroke patients," Journal of the Neurological Sciences, vol. 199, no. 1-2, pp. 49-54, 2002.

[9] M. Brainin, Y. Teuschl, and L. Kalra, "Acute treatment and long-term management of stroke in developing countries," Lancet Neurology, vol. 6, no. 6, pp. 553-561, 2007.

[10] A. Ferris, R. M. Robertson, R. Fabunmi, and L. Mosca, "American heart association and american stroke association national survey of stroke risk awareness among women," Circulation, vol. 111, no. 10, pp. 1321-1326, 2005. 
[11] J. Pandian, G. Kalra, A. Jaison et al., "Knowledge of stroke among stroke patients and their relatives in Northwest India," Neurology India, vol. 54, no. 2, pp. 152-156, 2006.

[12] A. R. Massaro, "Stroke in Brazil: a South America perspective," International Journal of Stroke, vol. 1, no. 2, pp. 113-115, 2006.

[13] A. Nicoletti, V. Sofia, S. Giuffrida et al., "Prevalence of stroke: a door-to-door survey in rural Bolivia," Stroke, vol. 31, no. 4, pp. 882-885, 2000.

[14] K. Ghandehari, A. Pourzahed, M. Taheri et al., "Estimation of Iranian stroke patients eligible for intravenous thrombolysis with tPA," International Journal of Stroke, vol. 4, no. 4, p. 236, 2009.

[15] K. Nandigam, S. K. Narayan, S. Elangovan, T. K. Dutta, K. R. Sethuraman, and A. K. Das, "Feasibility of acute thrombolytic therapy for stroke," Neurology India, vol. 51, no. 4, pp. 470473,2003

[16] K. Ghandehari, M. Foroughipour, A. Pourzadeh et al., "Thrombolysis in stroke patients: problems and limitations," Iranian Journal of Medical Sciences, vol. 35, pp. 145-148, 2010.

[17] United Nations, World Statistics Pocketbook, United Nations, New York, NY, USA, 2009.

[18] M. Wasay, H. Barohi, A. Malik, A. Yousuf, S. Awan, and A. K. Kamal, "Utilization and outcome of thrombolytic therapy for acute stroke in Pakistan," Neurological Sciences, vol. 31, no. 2, pp. 223-225, 2010.

[19] J. D. Pandian, V. Sethi, R. Dhillon et al., "Is intravenous thrombolysis feasible in a developing country?" Cerebrovascular Diseases, vol. 20, no. 2, pp. 134-136, 2005.

[20] L. A. Sposato, M. M. Esnaola, R. Zamora, M. C. Zurrú, O. Fustinoni, and G. Saposnik, "Quality of ischemic stroke care in emerging countries: the Argentinian National Stroke Registry (ReNACer)," Stroke, vol. 39, no. 11, pp. 3036-3041, 2008.

[21] C. J. Estol and M. M. Esnaola Rojas, "Stroke in Argentina," International Journal of Stroke, vol. 5, no. 1, pp. 35-39, 2010.

[22] J. Mar, A. Arrospide, and M. Comas, "Budget impact analysis of thrombolysis for stroke in Spain: a discrete event simulation model," Value in Health, vol. 13, no. 1, pp. 69-76, 2010.

[23] Z. May, I. Kakuk, C. Ováry et al., "Thrombolysis in acute ischemic stroke with intravenous recombinant tissue-type plasminogen activator," Orvosi Hetilap, vol. 143, no. 44, pp. 2479-2484, 2002.

[24] M. Padma, M. Singh, R. Bhatia et al., "Hyperacute thrombolysis with IV rtPA of acute ischemic stroke: efficacy and safety profile of 54 patients at a tertiary referral center in a developing country," Neurology India, vol. 55, no. 1, pp. 46-49, 2007.

[25] G. Wei, X. Ji, H. Bai, and Y. Ding, "Stroke research in China," Neurological Research, vol. 28, no. 1, pp. 11-15, 2006.

[26] A. El Khamlichi, "African neurosurgery: current situation, priorities, and needs," Neurosurgery, vol. 48, no. 6, pp. 13441347, 2001.

[27] K. O. Kolapo, S. A. Ogun, M. A. Danesi, B. S. Osalusi, and K. A. Odusote, "Validation study of the Siriraj stroke score in African Nigerians and evaluation of the discriminant values of its parameters: a preliminary prospective CT scan study," Stroke, vol. 37, no. 8, pp. 1997-2000, 2006.

[28] G. Zenebe, M. Alemayehu, and J. Asmera, "Characteristics and outcomes of stroke at Tikur Anbessa Teaching Hospital, Ethiopia," Ethiopian Medical Journal, vol. 43, no. 4, pp. 251259, 2005.

[29] L. de Villiers, S. Z. Kalula, and V. C. Burch, "Does multidisciplinary stroke care improve outcome in a secondarylevel hospital in South Africa?" International Journal of Stroke, vol. 4, no. 2, pp. 89-93, 2009.
[30] V. Padma, D. Soni, R. Bhatia, A. Srivastava, and M. Singh, "Thrombolysis in ischemic stroke: experience from a tertiary care hospital in India," Journal of the Neurological Sciences, vol. 238, pp. 428-429, 2005.

[31] N. C. Suwanwela, K. Phanthumchinda, and Y. Likitjaroen, "Thrombolytic therapy in acute ischemic stroke in Asia: the first prospective evaluation," Clinical Neurology and Neurosurgery, vol. 108, no. 6, pp. 549-552, 2006.

[32] P. Huang, C. H. Chen, Y. H. Yang, R. T. Lin, F. C. Lin, and C. K. Liu, "Eligibility for recombinant tissue plasminogen activator in acute ischemic stroke: way to endeavor," Cerebrovascular Diseases, vol. 22, no. 5-6, pp. 423-428, 2006.

[33] L. Sposato, "Retraso en la consulta en pacientescon accidents encefalovasculares," Revista Neurológica Argentina, vol. 26, no. 2, pp. 48-49, 2001.

[34] S. Ueshima and O. Matsuo, "The differences in thrombolytic effects of administrated recombinant t-PA between Japanese and Caucasians," Thrombosis and Haemostasis, vol. 87, no. 3, pp. 544-546, 2002.

[35] V. Hachinski, G. A. Donnan, P. B. Gorelick et al., "Stroke working toward a prioritized world agenda," International Journal of Stroke, vol. 3, no. 5, pp. 254-256, 2010.

[36] S. Muengtaweepongsa, P. Dharmasaroja, and U. Kummark, "Outcomes of intravenous thrombolytic therapy for acute ischemic stroke with an integrated acute stroke referral network: initial experience of a community-based hospital in a developing country," The Journal of Stroke \& Cerebrovascular Diseases, vol. 3, p. 17, 2010.

[37] A. Kobayashi, M. Skowronska, T. Litwin, and A. Czlonkowska, "Lack of experience of intravenous thrombolysis for acute ischaemic stroke does not influence the proportion of patients treated," Emergency Medicine Journal, vol. 24, no. 2, pp. 96-99, 2007. 


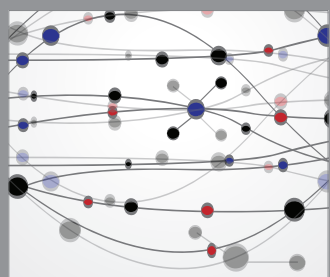

The Scientific World Journal
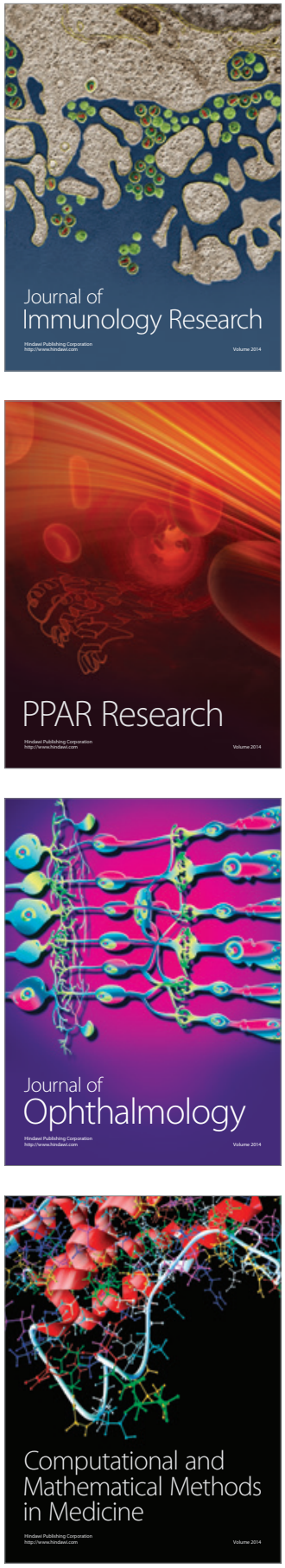

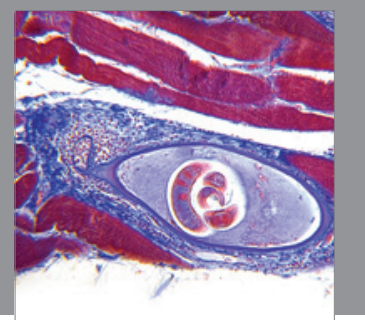

Gastroenterology

Research and Practice
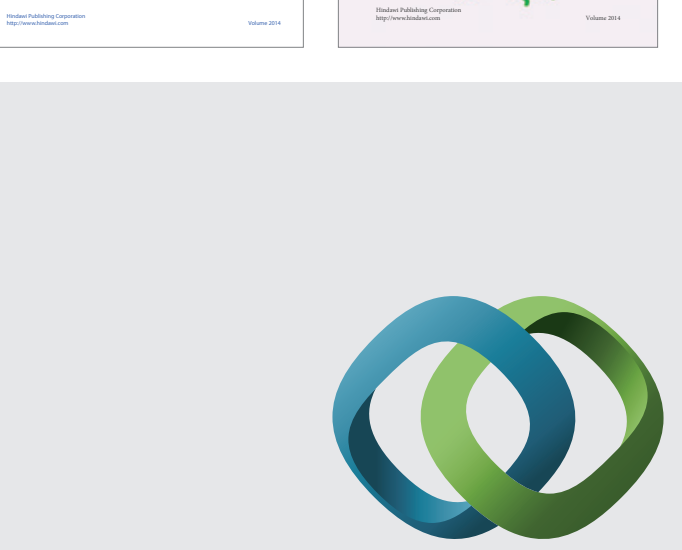

\section{Hindawi}

Submit your manuscripts at

http://www.hindawi.com
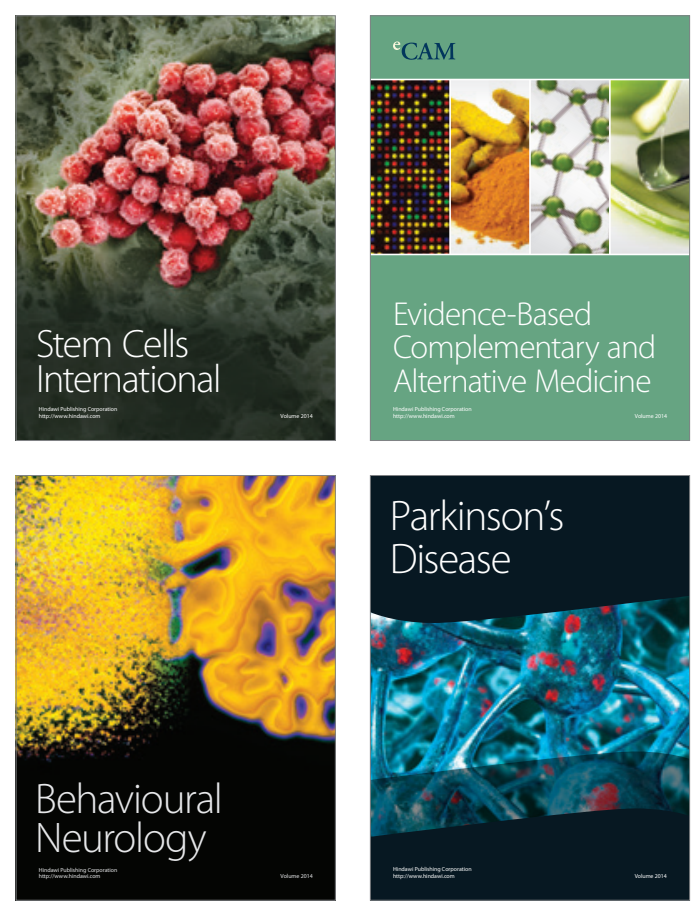

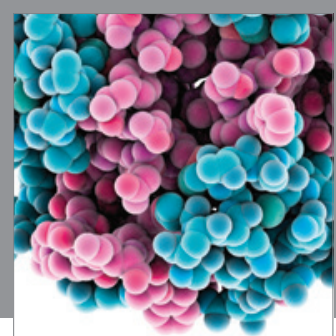

Journal of
Diabetes Research

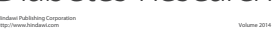

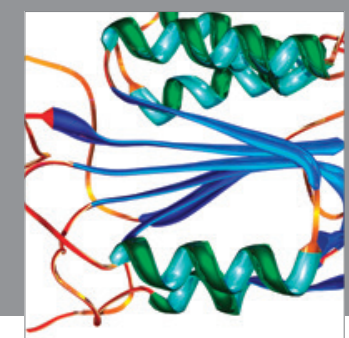

Disease Markers
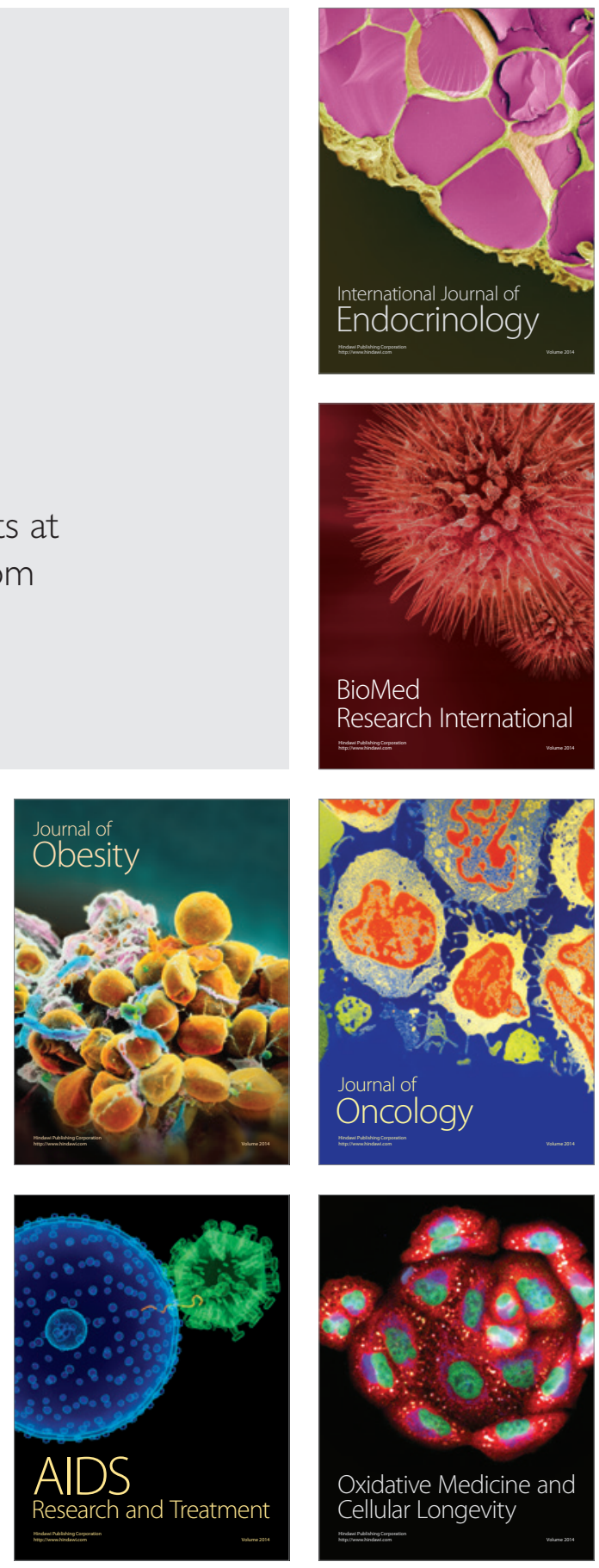